\title{
Incorporating Uncertainty and the Factor of Safety into a Natural Resources-Based Engineering Curriculum
}

\author{
Joel E. Cahoon*
}

\begin{abstract}
Engineering students are often introduced to the factor of safety concept at an early stage in their undergraduate sequence; for example, in introductory structures or materials courses. The factor of safety is often presented as a necessary, although dubious, part of the design process. Students and instructors have referred to the factor of safety as a fudge factor. This is a dangerous attitude as the factor is often multiplicative and heavily influences not only the ultimate failurerisk of a project, but the total cost of the project as well. Also, there are emerging design processes, bioremediation of wastewater for example, where the appropriate factor of safety for a design procedure has not been well established. This article documents a lecture-laboratory series in a natural resources-based option of a civil engineering curriculum along with student responses. I describe to students the evolution of the factor of safety and relate both the failure-risk due to input uncertainty and ultimately the cost of the final design to the factor of safety in cases where textbook-based guidance is not yet available. Evaluation surveys and comments from students indicate that the lecture-lab series successfully overcomes some of the mystery behind the factor of safety concept.
\end{abstract}

$\mathrm{E}$ NGINEERING students have historically been exposed to the concept of the factor of safety at varying levels of complexity. An often-used engineering mechanics text presents the factor of safety as simply the ratio of the failure load to the working load for a beam or other structural member (Byars et al., 1983). A more recent steel-structures text (Salmon and Johnson, 1996) discusses the evolution of the traditional working stress design to the more contemporary limit states design. In either case the concept of the factor of safety is well presented by depicting the failure zone as the overlap of the frequency distributions of a component's load and resistance. This concept is shown in Fig. 1 in a more general sense. Because the right-hand tail of the external actions distribution and the left-hand tail of the internal resistance distribution approach zero asymptotically, there can never be a completely safe design. Wang and Salmon (1992) present a similar discussion and offer examples of the nonmaterial related items that must also be considered in arriving at a safe design, such as the seriousness of failure and the reliability of workmanship.

In undergraduate courses that are not closely related to structural design, however, the factor of safety is sometimes more disguised. For example, dams have been categorized as major, intermediate, or minor (Viessman and Lewis, 1996). In major dams, failure cannot be tolerated, whereas

Department of Civil Engineering, Montana State Univ., Bozeman, MT 59717. Received 21 May 1997.*Corresponding author (joelc@ce.montana.edu).

Published in J. Nat. Resour. Life Sci. Educ. 27:20-24 (1998). http://www.agronomy.org/journals/jnrlse/1998.html in minor dams there is no loss of human life associated with failure and the cost of the damage due to failure would be similar in magnitude to the replacement cost of the dam. To arrive at a safe design for these two different structures, the design flood is chosen to best represent the intent of the structure. A major dam uses the most severe flood considered reasonably possible in the basin. The minor dam is designed on a reasonable frequency basis during which one failure would be tolerated. This approach has been taken with many designs that are affected by climatological variables.

\section{PRESENTING THE FACTOR OF SAFETY TO UNDERGRADUATES}

Montana State University's Civil Engineering Department offers an accredited Bachelor of Science degree in civil engineering with a bio-resources option. Choosing this degree option steers students into a program that is fundamentally a traditional civil engineering curriculum, except that some of the upper division structures and transportation courses are replaced by courses focusing on soil, plant, and water resources. Courses in advanced hydrology, hydraulic structures, soil-plant-water relationships, and natural wastewater treatment systems are required. Electives usually include groundwater, open channel flow, pipeline design, or senior-level environmental engineering courses. A problem that has evolved is that this curriculum does not include the upper division structures and transportation courses where the failure risk-cost relationship is traditionally rein-

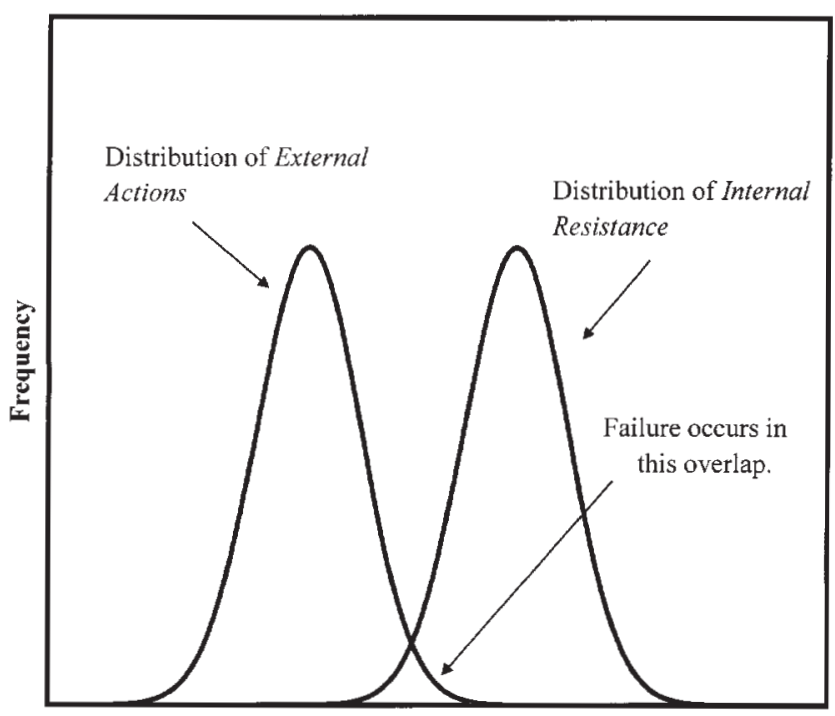

Fig. 1. A distributional presentation of the factor of safety concept adapted from Salmon and Johnson (1996). External reactions are factors that result in failure-examples are loads on a beam or flow rates during a flood. Internal resistance represents the ability of a design to resist failure-examples are the stiffness of a beam or the dimensions of a dam. 
forced. In their place are courses where the failure risk-cost relationship is often hidden in the design procedure or at best must be evaluated on a case-by-case basis by the designer.

Another unfortunate, albeit necessary, problem is that students at the undergraduate level are so bombarded with coefficients and factors that they become confused. I've had students contend that freeboard in small reservoir or open channel design is a safety factor. It is not-freeboard is very specifically a design component used to accommodate surface waves and spray (Schwab et al., 1993). When presenting the volume balance solution of the hydrodynamic equations, I've had students refer to flow weighting factors as fudge factors as if they were arbitrarily chosen and just happen to make the solution work. They are not-they are based on regression analyses between years of field trials and simulation studies.

To overcome these problems in the bio-resources curriculum, my colleagues and $I$ have chosen to insert into a senior level soil-plant-water relationships course a classroom lecture and corresponding computer-based lab assignment dealing with uncertainty and the factor of safety.

\section{Lecture}

The lecture begins with a general description of the factor of safety. I use the example of a beam that will fail if overloaded. I discuss the variability in material properties, tolerances in the manufacture of the beam, variability in workmanship in installing the beam, and variability in the load that the beam will experience. Then I discuss a series of tests that could be performed on many individual beams that would result in frequency distributions for the factors above. Combining these distributions with the fundamentals of beam design will result in a factor-of-safety/probabilityof-failure relationship that can be superimposed over the corresponding factor-of-safety/cost relationship. I tell the students that, in the absence of any standards or guidelines, it would then be the responsibility of the design engineer to work in close consultation with the client to arrive at the ultimate design based on a balance between risk of failure and the cost of the project. With that background, I then tell the students that extensive codes and standards for beams already exist and the design engineer doesn't really have to go through all these hoops every time a beam is designed.

But what if the design were for a system where the factors of safety are not well researched and tabulated? To approach this case, my next example is that of a remote livestock range where a mechanical water-pumping windmill is used to supply water for the animals. In this situation, the performance of the windmill is, on a relative scale, much more predictable than the characteristics of the wind regime. Here a failure can be defined in two ways. If the storage tank is dry for more than a few hours, a failure has occurred. While not such a dramatic failure, many stockmen would prefer that the storage tank not often overflow, so frequent overflow of the tank could also be considered a failure.

The variation of wind speeds at a given location and over time has been shown to follow a Rayleigh or Wiebull distribution (Johnson, 1985). These are similar distributions that, unlike the normal distribution, are skewed to the right and pass through the origin. For this demonstration I choose to use the Rayleigh distribution for simplicity-it is based only on the mean wind speed:

$$
f(u)=\frac{\pi u}{2 U^{2}} \exp \left[\frac{-\pi u^{2}}{4 U^{2}}\right]
$$

where

$u=$ the instantaneous wind speed $(\mathrm{m} / \mathrm{s})$

$U=$ the average wind speed $(\mathrm{m} / \mathrm{s})$

$f(u)=$ the probability of the occurrence of a wind speed

Montana has the information necessary to plot the Rayleigh distribution at many locations in the state (Montana DNRC, 1984). (Note that this presentation uses SI units. The actual lecture sequence uses mixed units-that is intentional. We expect our students to be equally conversant in both English and SI units.)

The volumetric flow rate from many water-pumping windmills follows the discontinuous function:

$$
\begin{aligned}
& Q=0, \text { when } u<u_{\mathrm{s}} \\
& Q=C_{1}\left(u-u_{\mathrm{s}}\right) \text { when } u_{\mathrm{s}} \leq u<u_{\mathrm{f}} \\
& Q=C_{2} \text { when } u \leq u_{\mathrm{f}}
\end{aligned}
$$

where

$Q=$ the volumetric flow rate $(\mathrm{L} / \mathrm{h})$

$u_{\mathrm{s}}=$ the minimum wind speed required to initiate pumping $(\mathrm{m} / \mathrm{s})$

$u_{\mathrm{f}}=$ the wind speed at which the windmill begins furling or braking $(\mathrm{m} / \mathrm{s})$

$C_{1}$ and $C_{2}$ are constants for a given windmill

Windmill manufacturers can usually supply the information needed to arrive at the values used in Eq. [2].

With this background, I present a computer program that uses Eq. [1] and [2] in a Monte Carlo type simulation. The Monte Carlo technique requires that the frequency distribution of inputs to a model are known. Inputs are sampled randomly according to these known distributions and used in the model. This produces a range of potential answers and the corresponding probabilities of occurrence for each answer, rather than a single solution. The program requires input consisting of the average wind speed, the values that define Eq. [2], the number of hours per simulation (this should match the period over which wind speeds were averaged and logged to arrive at $U$ ), and the number of simulations to perform. Then for each simulation the program samples randomly from the Rayleigh distribution, computes the flow rate from Eq. [2], and multiplies this by the simulation duration to yield an estimate of the volume pumped for that simulation.

The program tests the simulated pumping volumes for normality and presents some simple descriptive statistics. If the pumping volumes are normally distributed, the interval that is $1 \mathrm{SD}$ about the mean is given numerically and is shown graphically on the screen as depicted in Fig. 2. The example shown completed 100 simulations of 1-wk duration 
each. The middle line is the mean, the outer lines indicate the 1-SD confidence interval, and the markers are the calculated volumes for each simulation. This graph seems to give the students a good feel for the range of pumped volumes that could occur for the given duration and shows the dangers associated with designing based on the mean, $U$.

Figure 3 depicts the second graphic output screen, where the cumulative relative frequency (CRF) is plotted against the normalized pumping volumes from each simulation. With respect to this screen, I ask the students to identify the point on the curve where they would feel comfortable with a design. Their responses range from CRFs of 50 to 99\%, and they seem to have a feel for the odds that choosing a windmill based on its 50\% CRF volume may oversize the windmill and designing based on a high CRF may undersize the windmill.

I don't go much further with this example, except to outline the rest of the procedure that would be used to finalize the design in a real-life situation:

1. For a variety of storage tank sizes and shapes, incorporate the pumping volume distribution into a water balance where the inflow is from the windmill and the outflows are the consumption by the animals and evaporation from the surface. In a very sensitive design, the Monte Carlo technique could be applied to all three of these items.

2. From each water balance, record the maximum length of time that the tank will be dry and the number of occurrences of overflow from the tank.

3. Calculate the cost for each system analyzed.

4. Select the least expensive tank that has a tolerable number of dry periods and overflow events.

5. Repeat the above steps with several windmill sizes. Choose the combination of windmill and tank size that minimizes the total cost while maintaining acceptable dry periods and overflow events. In this case, there is no single place to apply a traditional multiplicative factor of safety, because the windmill and tank sizes are both variable.

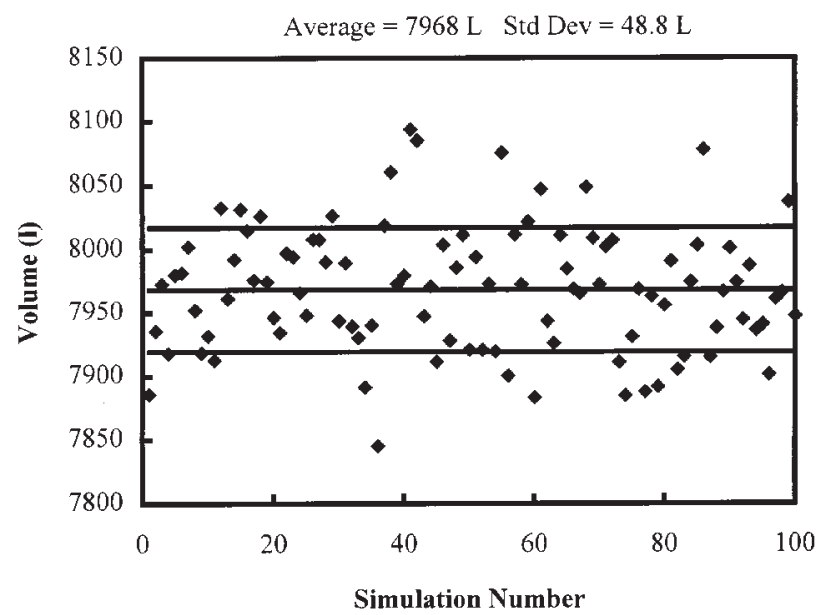

Fig. 2. A depiction of the on-screen image showing the volume pumped from each of 100 independent windmill simulations. The solid line is the mean result and the dashed lines are 1 SD from the mean.

\section{Laboratory Assignment}

After the lecture the students are given a computer-based laboratory assignment. There are many problems where a Monte Carlo approach is appropriate and leads to a more marketable engineering design. I have presented this lecture-lab sequence for 2 academic years.

\section{Spring 1996}

During the Spring 1996 semester, I chose the Soil Conservation Service (now Natural Resources Conservation Service) runoff design procedure for the lab assignment. A runoff curve number and the rainfall depth from an $x$-year, $y$-duration precipitation event are the necessary input. In many designs, the factor of safety is built into the selection of $x$ and $y$. In this assignment, these are fixed, and the design runoff volume is selected based on the CRF that results from a Monte Carlo simulation. The runoff volume equations are (Schwab et al., 1993):

$$
\begin{gathered}
V=\frac{(I-0.2 S)^{2}}{I+0.8 S} \\
S=\frac{25400}{N}-254
\end{gathered}
$$

where

$V=$ the direct surface runoff depth $(\mathrm{mm})$

$I=$ the storm rainfall depth for an $x$-year, $y$-duration storm $(\mathrm{mm})$

$S=$ the maximum potential difference between rainfall and runoff $(\mathrm{mm})$

$N=$ a curve number representing the basin terrain and characteristics

The students are given the mean and standard deviation for both $I$ and $N$. They use a spreadsheet to select 100 randomly assigned values of $I$ and $N$, given the distribution of each, and for each 100 pairs of $I$ and $N$ they calculate the resultant $V$. Many spreadsheet programs currently available make this a simple procedure as the software is capable of selecting values from a known normal distribution based on random sampling. From this pool of $V$ 's, the students are asked for a design value of $V$, the CRF for that value, and the resulting

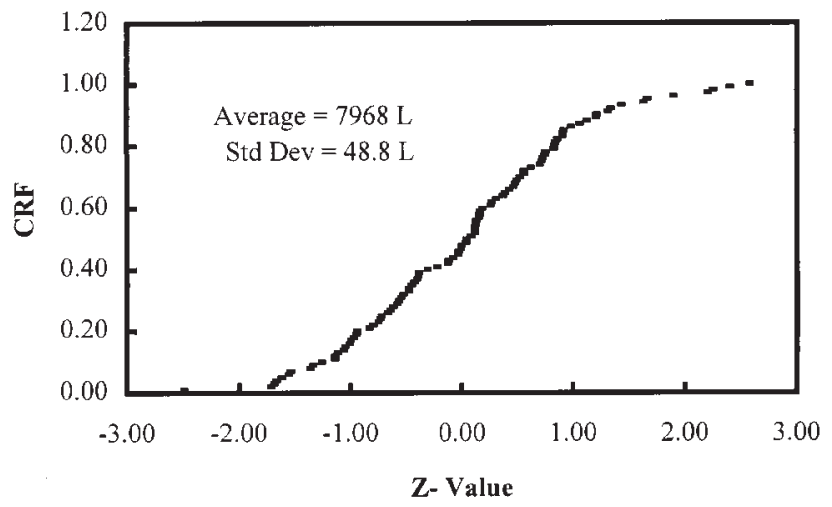

Fig. 3. A depiction of the on-screen image showing the cumulative relative frequency of pumped volume for all 100 windmill simulations. 
factor of safety for two scenarios. The scenarios are a small on-farm reservoir sited uphill from a residence and a culvert passing beneath the driveway of the residence. The factor of safety is calculated as the chosen value of $V$ divided by the value of $V$ that results from using the mean $I$ and $N$ in Eq. [3] and [4].

The culvert under the driveway has little consequence of failure for a given $x$-year, $y$ - duration storm. The students seem to understand this as they tended to choose a CRF of slightly above $50 \%$, resulting in a factor of safety of near 1 . For the reservoir, they choose values of CRF in the 75 to $95 \%$ range, resulting in factors of safety in the 1.4 to 1.7 range-this even though they had been told in advance that the $x$-year, $y$-duration storm and the curve number are intentionally conservative.

\section{Spring 1997}

The lab assignment in the Spring 1997 semester was very similar in intent to that of the previous year, but I chose to alter the problem. I assigned a well draw-down problem using the Theim equation. The Theim equation relates steady-state well draw-down to distance from the well in cases where a well fully penetrates an impermeable-floored aquifer (Linsley et al., 1992):

$$
Q=\frac{\pi K\left(h_{2}^{2}-h_{1}^{2}\right)}{\ln \left[r_{2} / r_{1}\right]}
$$

where

$Q=$ the steady-state discharge of the well (L/min)

$K=$ the homogeneous saturated hydraulic conductivity $\left(\mathrm{L} / \mathrm{min}\right.$ per $\left.\mathrm{m}^{2}\right)$

$h_{2}=$ the groundwater height above the impermeable floor at a distance $r_{2}$ from the well (m)

$r_{2}=$ the radial distance from the well at which $h_{2}$ is measured $(\mathrm{m})$

$h_{1}=$ the steady-state water level in the well casing (m)

$r_{1}=$ the well casing radius $(\mathrm{m})$
The students were first asked to solve for the saturated hydraulic conductivity given certain measurements of a draw-down curvature corresponding to a given discharge. Then the students were asked to arrive at a value of drawdown in the well casing given that $h_{2}, r_{2}, r_{1}$, and $Q$ are measured with certainty, but that $K$ is normally distributed with a given mean and standard deviation. The intent here is not to describe spatial variability (we cover that later in the course), but to include the variability that might occur because of the limitations of our measurement techniques. The students were surprised at first to find that the resulting pool of $h_{2}$ values from the Monte Carlo approach were not normally distributed. The students reported the mean and quartile values of $h_{2}$ and were asked to comment on the most appropriate answer. The student's comments, qualitatively, indicated that they understood that a nonlinear transformation of a normally distributed phenomenon resulted in a distribution that is no longer normally distributed.

\section{FEEDBACK FROM UNDERGRADUATES}

Twenty-four students enrolled in the course in Spring 1996 and 18 in Spring 1997. The senior-level bioresources engineering students were asked to rank the effectiveness of the lecture-lab exercise by responding to three statements with a rank of 10 indicating strong agreement and 1 indicating strong disagreement:

1. The Monte Carlo simulation discussed in the lecture provided a good example of incorporating input variability into a real-life problem.

2. I feel more comfortable incorporating real-life variability into an engineering problem now that I have completed the lab assignment.

3. I feel more comfortable using the factor of safety concept now that I have completed the lab.

I first compared the results of the questionnaire over the two groups of students (Spring 1996 means vs. Spring 1997 means). For all three "questions" there were no significant

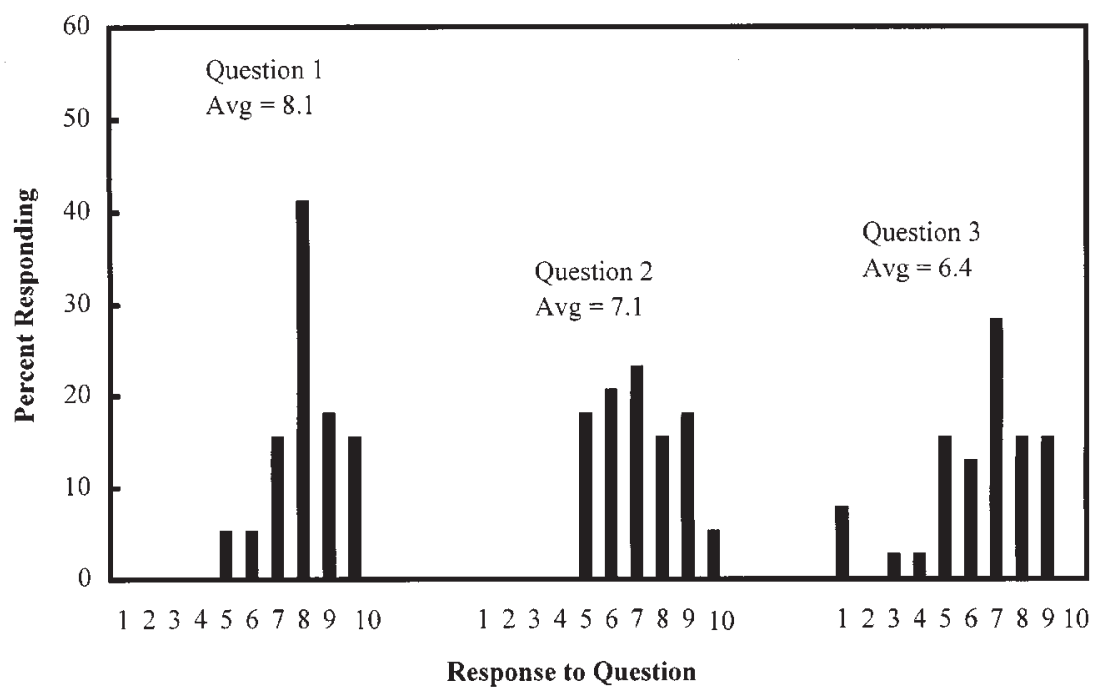

Fig. 4. Frequency of responses to the postassignment evaluation questionnaire $(10=$ agreement, $1=$ disagreement $)$. 
differences in mean answers between the two groups of students. With no obvious evidence indicating lack of homogeneity between the two groups, I pooled the questionnaire answers over the two groups and performed simple descriptive statistics over the pool. The results are shown in Fig. 4. The mean responses to Questions 1 through 3, respectively, were $8.1,7.1$, and 6.4 . On the 1 to 10 scale, these results indicate a fairly successful lecture-lab series, with an increased understanding of the topic. The only disappointment was that $12 \%$ of the students responded with a indicator less than 5 for Question 3. Apparently, for a small percentage of the students, the connection between the factor of safety and the statistical analyses that can be superimposed on a real-life problem was not apparent.

\section{CONCLUSIONS}

Montana State University's bio-resources option in civil engineering lacks the courses that typically introduce students to failure theory associated with the uncertainty of design inputs. A lecture-laboratory series in a senior level design course seems to have overcome this concern. The students responded well to the simple Monte Carlo simulation of a water pumping windmill and were able to successfully complete similar spreadsheet-based assignments.
Students were issued a survey after the assignments were graded and returned. The survey responses indicated that a majority of the students comprehended the material and recognized that it is sometimes advantageous to offer a client an engineering design that is based on something more inclusive than the simple average.

\section{REFERENCES}

Byars, F.W., R.D. Snyder, and H.L. Plants. 1983. Engineering mechanics of deformable bodies. 4th ed. Harper and Row Publ., New York.

Johnson, G.L. 1985. Wind energy systems. Prentice-Hall, Englewood Cliffs, NJ.

Linsley, R.K., J.B. Franzini, D.L. Freyberg, and G. Tchobanoglous. 1992. Water resources engineering. 4th ed. McGraw-Hill Publ., New York.

Montana Department of Natural Resources and Conservation. 1984. Montana wind energy atlas. Prepared by GeoResearch Inc., Billings, MT.

Salmon, C.G., and J.E. Johnson. 1996. Steel structures design and behavior. 4th ed. Harper-Collins College Publ., New York.

Schwab, G.O., D.D. Fangmeier, W.J. Elliot, and R.K. Frevert. 1993. Soil and water conservation engineering. 4th ed. John Wiley \& Sons, New York.

Viessman, W.J., and G.L. Lewis. 1996. Introduction to hydrology. 4th ed. Harper and Row Publ., New York.

Wang, C.K., and C.G. Salmon. 1992. Reinforced concrete design. 5th ed. Harper Collins College Publ., New York. 